\title{
TRADICIONALISMO E EDUCAÇÃO NO RIO GRANDE DO SUL
}

\author{
CERES KARAM BRUM \\ Professora adjunta do Departamento de Fundamentos da Educação \\ e do Mestrado em Ciências Sociais da Universidade Federal de Santa Maria - RS \\ cereskb@terra.com.br
}

\begin{abstract}
RESUMO
O artigo reflete sobre o gauchismo como uma das expressões da cultura popular no Rio Grande do Sul. O objetivo é caracterizar o Movimento Tradicionalista Gaúcho como movimento cultural organizado e perceber as dimensões dos processos de formação dos tradicionalistas em seus territórios, bem como as relações que o movimento estabelece com as escolas. A pesquisa foi desenvolvida a partir de um conjunto de trabalhos de campo com base na observação participante em escolas e em territórios do gauchismo e do tradicionalismo. A indústria cultural aparece como recurso plural utilizado para a popularização de uma imagem do gaúcho veiculada pelo gauchismo. TRADICÃO - CULTURA POPULAR - EDUCAÇÃO
\end{abstract}

\section{ABSTRACT}

TRADITIONALISM AND EDUCATION IN RIO GRANDE DO SUL. This article reflects on gauchismo as one of the expressions of popular culture in Rio Grande do Sul. Its purpose is to characterize the Gaucho Traditionalist Movement as an organized cultural movement and to understand the dimensions of how traditionalists are educated in their territories, as well as the relations established by the movement with schools. The research was conducted based on fieldwork with participant observation in schools and in territories of gauchismo and traditionalism. The cultural industry appears as a plural resource for the popularization of the gaucho image promoted by the gauchismo movement.

TRADITION - POPULAR CULTURE - EDUCATION

As reflexões desenvolvidas neste artigo se relacionam ao projeto de pesquisa $\bigcirc$ Movimento Tradicionalista Gaúcho e a Escola: Perspectivas Pedagógicas e Educacionais. Uma Análise Antropológica das $(\operatorname{Re})$ configurações de Identidades Plurais, financiado pelo Fundo de Incentivo à Pesquisa da Universidade Federal de Santa Maria. 
Entre as expressões da cultura popular no Rio Grande do Sul chama a atenção o conjunto de manifestações culturais que remetem à interpretação da figura histórica do gaúcho. Ela vem sendo veiculada como símbolo regional desde o final do século XIX até o presente. Esse processo, iniciado com a produção e lapidação do gaúcho para sua exaltação, ocorreu a partir da criação de uma literatura regional no Rio Grande do Sul, tendo como inspiração a literatura nacionalista uruguaia e argentina que também o utilizava.

Desde então, a presença do gaúcho como símbolo se expandiu, atingindo caráter popular com a criação e principalmente a expansão de movimentos tradicionalistas.' Nesse contexto, surgiu um conjunto de expressões que objetivavam reproduzir no presente o modo de vida do gaúcho do passado, para ser cultuado. Também surgiram entidades tradicionalistas, os Centros de Tradições Gaúchas² - CTGs -, danças, músicas, poesias, culinária, linguagem e indumentária etc.

Essas recriações têm objetivos identitários que se expressam em estratégias de afirmação do regional, envolvendo múltiplos atores em luta simbólica pelo monopólio de interpretação "do que foi o gaúcho". Um desses grupos é o Movimento Tradicionalista Gaúcho. Ele tem a dupla preocupação de formação de jovens que perpetuem o gauchismo e de sua disseminação em outros territórios, como as escolas e universidades. Neste artigo, analiso os objetivos e as justificativas desse movimento.

\section{O GAUCHISMO E O TRADICIONALISMO}

tradicionalismo gaúcho é considerado por seus membros como o maior movimento cultural popular do mundo na atualidade. Essa informação

I. Segundo Oliven (2006) a criação do movimento tradicionalista no Uruguai ocorreu com a fundação em I894, em Montevidéu, da Sociedad Criolla. Na Argentina, segundo Fradkin (2003), o mito do gaúcho remete a dois contextos: o de 1870 (sua consagração literária), pontuado por profundas transformações na agricultura e a demarcação de fronteiras, e o de 1913, determinado pela construção nacional de sua busca de definição em termos das tradições.

2. Centro de Tradições Gaúchas é um espaço de culto ao gaúcho, uma espécie de clube social onde se realizam fandangos (bailes) e outras atividades tradicionalistas. Em sua estrutura, apropria-se e (re)significa a nomenclatura das antigas estâncias. Seu presidente é designado como "patrão", o tesoureiro é o "agregado das patacas" etc. Os homens que o frequentam recebem a designação de "peão" e as mulheres de "prendas". 
é veiculada nos discursos das sessões solenes que pontuam a abertura e o encerramento da maior parte de suas atividades, bem como por políticos e demais autoridades. Oliven (2006), baseado nas informações do folclorista e tradicionalista Lessa (1985), se refere à participação direta de dois milhões de pessoas no Movimento Tradicionalista Gaúcho - MTG - e o seu site menciona a existência de 1.400 entidades tradicionalistas filiadas. $\bigcirc$ gauchismo, em suas mais variadas expressões, mobiliza milhares de pessoas em inúmeros eventos e atividades.

Segundo Maria Eunice Maciel (1994), deve-se entender por gauchismo diversas manifestações culturais que têm o gaúcho como ponto de referência e que investem nessa representação, alimentando um sentimento de pertencimento. A diferença com outras dimensões do regionalismo é que o gauchismo não quer estudar ou escrever sobre o gaúcho, mas oferecer um culto às tradições por "encarnação" de uma imagem do gaúcho. A personificação do gaúcho pelos tradicionalistas pretende representar o "verdadeiro" gaúcho. Eles se dão o título de "guardiões" de uma pureza, em nome de uma "autenticidade".

Fazem parte desse universo de culto, conforme a autora, intelectuais e literatos interessados nas tradições regionais, como, por exemplo, os poetas membros da Estância da Poesia Crioula - EPC -, uma espécie de academia regionalista de letras, poetas e músicos que participam dos festivais nativistas, muitos deles também membros da EPC, os participantes dos CTGs e dirigentes do MTG, folcloristas e dirigentes da Fundação Instituto de Tradição e Folclore.

$\bigcirc$ tradicionalismo, como manifestação do gauchismo, compreende um conjunto de atividades organizadas e regulamentadas que objetivam celebrar a figura do gaúcho e seu modo de vida em um passado relativamente distante, tal como os participantes e, sobretudo,

os pesquisadores (tradicionalistas) ${ }^{3}$ do movimento o percebem e o definem em seus escritos, instituindo práticas de culto em torno das quais se glorifica um passado atualizado no presente.

3. Pesquisadores do MTG são lideranças tradicionalistas que se preocupam com a autenticidade no culto das tradições, produzindo pesquisas que influenciam o movimento. Exemplos são os folcloristas Marina e João Carlos Paixão Cortes com produção bibliográfica sobre indumentária e cursos de dança tradicionalista que ministram em CTGs do Rio Grande do Sul e outros lugares do Brasil. O próprio MTG disponibiliza e indica pessoas, cursos e publica materiais para serem utilizados pelos CTGs nos concursos tradicionalistas. 
Otradicionalismo, originalmente, é comum às regiões onde hoje se localizam a Argentina, o Uruguai e o Estado do Rio Grande do Sul, territórios em que historicamente é referida a presença do gaúcho identificado à vida rural, cuja principal atividade econômica consistia no apresamento de gado xucro para a comercialização do couro.

Para Teixeira ( 1988), o termo gaúcho teve uma trajetória semântica notável. De início, significava contrabandista, vagabundo, antigregário, incivilizado, antissocial. Hoje significa valores positivos em grau aumentativo. Mas, apesar de o gaúcho ser comum a essas três regiões, o movimento tradicionalista apresenta particularidades locais bem marcadas. O gaúcho, no Uruguai e na Argentina, é apropriado e festejado pelos tradicionalistas daqueles países como uma figura emblemática nacional (Garavaglia, 2003), enquanto no Rio Grande do Sul representa como um sinal diacrítico para a construção das identidades regionais em relação às identidades nacionais brasileiras (Oliven, 2006).

O tradicionalismo gaúcho do Rio Grande do Sul, como movimento, se expande por vários estados do Brasil, sendo cultuado por gaúchos de origem, descendentes e também por simpatizantes. Atualmente, há entidades tradicionalistas organizadas dentro e fora do Rio Grande do Sul, inclusive no exterior. Segundo os tradicionalistas o culto às tradições gaúchas ocorre em Nova lorque, em Lisboa, Paris e no Japão, como consequência da "diáspora" dos gaúchos rio-grandenses pelo Brasil e pelo mundo (Kaiser, 1999).

O responsável pelas atividades tradicionalistas no Rio Grande do Sul é o Movimento Tradicionalista Gaúcho, assim definido em seu site:

É uma entidade associativa, que congrega mais de 1400 Entidades Tradicionalistas legalmente constituídas, conhecidas por Centro de Tradições Gaúchas ou Grupos Nativistas ou Grupo de Arte Nativa ou Piquete de Laçadores ou Grupos de Pesquisas Folclóricas ou outras denominações, que se identifiquem com a finalidade a que se propõem, que são as "entidades fins". As entidades tradicionalistas filiadas ao MTG estão distribuídas nas 30 Regiões Tradicionalistas, as quais agrupam 500 municípios do nosso Estado. É um movimento cívico, cultural e associativo. Sua sede é própria e está situada à rua Guilherme Schell, n. 60, no Bairro Santo Antônio em Porto Alegre. [...] O MTG é definido como uma entidade civil sem fins lucrativos, dedica-se à preservação, resgate e desenvolvimento da cultura gaúcha, por entender que o tradicionalismo é um organismo social de natureza 
nativista, cívica, literária, artística e folclórica, conforme descreve simbolicamente o Brasão de Armas do MTG, com as sete (7) folhas do broto, que nasce do tronco do passado. (www.mtg.org.br)

A criação do tradicionalismo, como movimento cultural, ocorreu a partir da segunda metade do século XX, com a criação do 35 Centro de Tradições Gaúchas, em Porto Alegre, em 1948. Conforme Cortes ( 1994), um dos jovens fundadores do movimento, o tradicionalismo foi uma espécie de reação à entrada da cultura norte-americana e seus produtos no Rio Grande do Sul, com a ascensão dos Estados Unidos no pós-guerra. Este período inicial caracteriza-se pela criação de espaços e momentos específicos para o culto das tradições gaúchas em um cenário urbano, recriando o gaúcho nas suas vestes, habitat, trabalho, alimentação, lazer.

Tal desejo de exaltação é perceptível nas demonstrações de civismo ${ }^{4}$ valorizadoras dos símbolos da "alma regional". Referências que se assemelham às de Löfgren ( I 989) e Thiesse (200 I), sobre a elaboração simbólica e material visando à construção coletiva das identidades nacionais. Segundo Thiesse:

Hoje podemos estabelecer a lista dos elementos simbólicos e materiais que uma nação digna deste nome deve apresentar: uma história que estabeleça uma continuidade com os ilustres antepassados, uma série de heróis modelos das virtudes nacionais, uma língua, monumentos culturais, um folclore, locais eleitos e uma paisagem típica, uma determinada mentalidade, representações oficiais - hino e bandeira - e identificações pitorescas - trajes, especialidades culinárias ou um animal emblemático. (2001, p. 19)

4. O site do MTG destaca como datas principais de sua constituição: 24 de abril de 1948, que marca o início da trajetória histórica do tradicionalismo organizado, ocasião em que um grupo de jovens, "com espírito cívico aguçado", fundou o 35 Centro de Tradições Gaúchas, em Porto Alegre, motivando a proliferação de núcleos de preservação da tradição gaúcha; ${ }^{\circ}$ a 4 de julho de 1954, quando se realiza o $1^{\circ}$ Congresso Tradicionalista, em Santa Maria, em que foi aprovada a tese $\mathrm{O}$ sentido e o valor do tradicionalismo, de Luiz Carlos Barbosa Lessa; 17 a 20 de dezembro de 1959, quando o movimento se institucionaliza com a criação do Conselho Coordenador, durante $06^{\circ}$ Congresso, realizado em Cachoeira do Sul, e João Cezimbra Jacques é escolhido Patrono do Tradicionalismo; 28 de outubro de 1966, quando é oficialmente criado o Movimento Tradicionalista Gaúcho, como entidade federativa e com personalidade jurídica, no $12^{\circ}$ Congresso, realizado em Tramandaí. Na ocasião, foi adotado o Brasão de Armas do Tradicionalismo, que é atualmente a logomarca do MTG (www.mtg.org.br). 
Os tradicionalistas manifestam preocupação com a construção "coletiva" de identidades regionais. Isto se evidencia no esforço de criação de símbolos que os identificam, como sinais diacríticos que possibilitam caracterizar o próprio tradicionalismo como movimento.

Os fundadores de 1947-1948, como Paixão Cortes e Barbosa Lessa, procuraram justificar a necessidade de criação do tradicionalismo para mostrar e celebrar o Rio Grande como um lugar ímpar em relação ao restante do Brasil. O processo de criação desses elementos é exemplificado por Lessa, demonstrando a apropriação de termos antigos aos seus novos objetivos:

Assim, por exemplo, qual o adjetivo que daríamos a nós mesmos quando estivéssemos vestidos à gaúcha? Alguém sugeriu "aperado". Mas "apero" é roupa de cavalo, o termo não ficava bem. Então, na ata de 8 de maio de 1948, o secretário Antônio Cândido se lembrou que pilcha é dinheiro ou objeto de uso pessoal que possa ter um valor pecuniário. "Vamos oferecer ao patrão de honra, Paixão, um churrasco ao qual a indiada deve vir toda pilchada". E esse invento colou! (1985, p.64)

O termo "pilcha", ao ser apropriado, recria o passado e suas tradições, fornece um certificado de autenticidade à forma de vestir, como sugere Maciel (200 I ). A recriação do termo "pilcha"e a utilização do verbo "pilcha-se" ${ }^{5}$, para designar o estar vestido a caráter, se inscrevem na lista de elementos materiais e simbólicos mencionados acima, em que ocorreu ainda o aproveitamento da paisagem épica - o pampa, do cavalo como animal emblemático, do chimarrão, como bebida, e do churrasco como prato típico. A criação de monumentos culturais é outro aspecto presente entre os tradicionalistas. A estátua do "laçador" - representação de um gaúcho peão de estância, em Porto Alegre, se insere na questão da exaltação do regional a que se agregam também elementos que se aproximam do gaúcho como figura representacional.

É importante analisar a relação que os tradicionalistas estabelecem com o folclore e a história, pois é daí que extraem material para suas representações, já que os tradicionalistas se consideram herdeiros de seus antepassados e se

5. O termo "pilchar-se" é definido por Nunes ( 1993, p.374) como o vestir-se com trajes típicos gaúchos. 
propõem a continuar uma história gloriosa, ao se identificarem e produzirem representações do verdadeiro gaúcho em suas danças, cantos, poesias, desfiles bailes, cavalgadas, por exemplo.

Assim, referem-se ao tradicionalismo como um espaço que preserva valores desse passado, como a honra, a família, a honestidade, a palavra dada como empenhada, retratadas ao mencionar falas de heróis e nas cores dos lenços, visando estabelecer uma continuidade com antepassados ilustres. $\bigcirc$ tradicionalista Edson Otto relata:

O MTG também foi repudiado no começo, era inclusive [sic]. Havia gente que descobriu "entre guampas" que a sigla CTG queria dizer "Cemo" Tudo Grosso [risos]. É lógico que há mais facilidade de os centros de tradições trazer os grossos também, é que eles não são repudiados no meio tradicionalista. Tradicionalismo não repudia nada, nem cor, nem religião, nem aspecto econômico social. Nós temos dentro dos CTGs criaturas assim de guaiacas recheadíssimas e gente que nem guaiaca tem porque não pode comprar. Brancos, pretos, intelectuais da mais alta nomeada como o Lessa, reconhecido hoje como um dos mais importantes gaúchos que nós tivemos em intelecto e temos os analfabetos, temos todo o tipo de gente, então esse amálgama que vem construindo o tradicionalismo que vem galgando posições muito grandes a partir de quando, a partir do reconhecimento que houve fora do RS, de um reconhecimento que houve fora do país. (Entrevista, 20/9/2002)

Mas, além dessa exaltação do CTG como um espaço plural, os tradicionalistas mostram uma grande preocupação com o culto dos antepassados. $\bigcirc$ processo histórico em que buscam heróis para serem exaltados e que produz um imaginário para ser vivido no presente é um passado de lutas. $\bigcirc$ modelo de virtude cultuado é o do homem guerreiro, como ocorre na exaltação dos heróis da Revolução Farroupilha ( 835 - | 845), caracterizada por Brum (2006) como mito fundador do gauchismo, e em outros episódios, como a Guerra Guaranítica (1754-1756) ${ }^{6}$.

6. Do ponto de vista histórico (Quevedo, 2000), a principal causa dessa rebelião colonial que colocou em disputa os índios das Missões contra os exércitos unidos de Portugal e Espanha, decorreu das determinações do Tratado de Madri de 1750, da troca dos territórios castelhanos dos Sete Povos das Missões pela Colônia do Sacramento - território português, garantindo 
A Revolução Farroupilha, deflagrada em 20 de setembro de I 835, foi uma guerra civil que provocou a separação e independência de parte do Rio Grande do Sul do restante do Brasil, com a proclamação da República Rio-Grandense. Do ponto de vista econômico, o charque sulino estava sendo sobretaxado, gerando o descontentamento dos estancieiros gaúchos pelo baixo preço pago pelo Império em relação aos saladeros platinos. A revolução terminou em I 845, com a assinatura da Paz de Ponche Verde com a re-integração do Rio Grande do Sul ao Império brasileiro.

No mês de setembro ocorre a Semana Farroupilha, sendo o dia 20 instituído como o dia do gaúcho, feriado em todos os municípios do Rio Grande do Sul, marcado por grandes desfiles cívicos a cavalo e em carros alegóricos reunindo tradicionalistas, escolas e Brigada Militar.

A exaltação promovida pelo imaginário tradicionalista dos heróis, significados como símbolo do gauchismo, na Semana Farroupilha, faz a apologia do período de 1835- 845 como uma fase de bravura, resistência e apego à terra, ressaltando o homem guerreiro. A produção desse imaginário contrasta com o caráter de uma paz acordada com o Império, que pôs fim à Revolução Farroupilha, e com a exaltação do "Esta terra tem dono" de Sepé Tiaraju em face do genocídio dos índios missioneiros que pôs fim à Guerra Guaranítica.

A consolidação desse imaginário apologético e performático do homem guerreiro envolve uma série de aprendizados formais e informais no universo tradicionalista e fora dele. Um exemplo significativo é a legislação estadual que institui os símbolos rio-grandenses ${ }^{7}$, cujo reconhecimento se inscreve em um movimento maior relacionado a uma verdadeira indústria cultural do gauchismo, que inclui rádios, programas televisivos, música.

assim espaço colonial contínuo às duas coroas. De uma perspectiva antropológica (Brum, 2006), o herói exaltado é o índio missioneiro Sepé Tiaraju, a quem se atribui a expressão "Esta terra tem dono". Morto nas escaramuças que antecederam a Batalha de Caiboaté, tornou-se símbolo no Rio Grande do Sul da luta pela terra e da resistência dos gaúchos.

7. A Bandeira, o Hino e as Armas foram instituídos pela Lei n. 5.213/66. A Lei n. 7.439/80 instituiu a planta da erva-mate. A ave quero-quero foi instituída pela Lei n. 7.418/80, a flor Brinco de Princesa pelo Decreto n. 38.400/98, o cavalo crioulo pela Lei n. I I.826/02, a planta medicinal marcela pela Lei n. I I.858/02, o chimarrão pela Lei n. I I.929/03 e o churrasco pela Lei n. I 1.929/03. O traje típico gaúcho é considerado traje de gala no Rio Grande do Sul por determinação da Lei n. 8.813/89. 
À "mídia nativa" (Jacks, 1998) soma-se a produção de artigos de vestuário regional, como bombachas, botas e vestidos de prenda, culinária, arreamento 8 , discografia, livros de poesia, folclore e história, dicionários regionalistas, locais específicos para o culto do gauchismo, como o Parque da Harmonia, em Porto Alegre, onde ocorre o Acampamento Farroupilha, durante o mês de setembro. Ao analisar os festivais musicais nativistas realizados na década de 1980, no Rio Grande do Sul, Jacks afirma:

No contexto da indústria cultural gaúcha, em termos de nativismo e de resgate da identidade regional, a publicidade desempenhou um papel bastante importante na medida em que se utilizou fortemente da linguagem regional em suas campanhas, absorvendo as tendências da época. (1998, p.91)

Esse movimento crescente que relaciona indústria cultural e cultura regional também se observa com relação ao tradicionalismo. No Encontro de Arte e Tradições Gaúchas - Enart -, de 200 I, a imagem do gaúcho e das Missões foi veiculada pela publicidade. A Claro Digital ${ }^{9}$ apresentou um banner em que o papagaio Claro aparece sobre o mapa do Rio Grande do Sul com uma das patas em São Miguel das Missões. $\bigcirc$ maior destaque no mapa é para Porto Alegre, mas este também mostra parte do Paraguai e da Argentina com suas respectivas Reduções e o seguinte dizer: "Pega nas Missões? É Claro".

As Missões são mostradas como um lugar turístico distante. Na publicidade televisiva veiculada pela Claro eram mostrados turistas no sítio arqueológico de São Miguel, falando ao celular. A apropriação deste momento histórico passado, pela Claro, é utilizada para alimentar o turismo e as ruínas de São Miguel das Missões são mostradas como um patrimônio a ser preservado e visitado.

Rocha (1985) elucida que o processo percorrido pelo produto - da criação até o consumo - é permeado pela publicidade, responsável por sua personificação e identificação que se relaciona a quem esse produto é dirigido,

8. Arreamento", relativo a arreio: conjunto de peças utilizadas nos cavalos para montaria e para tração.

9. Por meio de um acordo comercial a Claro Digital foi patrocinadora oficial em 200 I do MTG; as informações de que disponho a respeito constam do relatório de atividades do MTG (2002, parte 3, p.21). 
para após ser definido por seus consumidores, numa relação que é recíproca. A publicidade baseia-se na lógica da passagem, da transformação. Essa passagem se opera no imaginário dos consumidores e atua simbolicamente gratificandoos de alguma maneira por terem escolhido aquele produto. Assim, há um processo inegável de identificação entre ambos - produto e consumidor, que é também um processo de classificação.

Se a Claro Digital se aproxima dos tradicionalistas utilizando seus símbolos não é apenas porque tem um mercado a ser conquistado. É também porque é capaz de atuar no seu imaginário apropriando-se ludicamente da história gaúcha usando a linguagem do seu consumidor, que é ao mesmo tempo moderno e tradicional, que precisa se comunicar - "É Claro" - e classifica os consumidores, legitimando-os como gaúchos. Reconhece as fronteiras e as transpõe comunicativamente na publicidade que encarna o produto ao utilizar as Missões.

A mensagem contida é linear. Não interessam as contradições do passado missioneiro, mas sim o fato de os gaúchos reconhecerem as ruínas como um lugar histórico a ser preservado e visitado, o que cria a necessidade prática de comunicação e o uso de um celular que "pegue" nas Missões, sendo criados a simbologia e o discurso publicitário ${ }^{10}$ para o produto, que venham ao encontro das necessidades desses consumidores.

\section{O TRADICIONALISMO: DIMENSÃO EDUCACIONAL}

A afirmação do autêntico culto do gaúcho pelo tradicionalismo como movimento organizado, em termos de sua conquista pelo monopólio do poder de nomear, na perspectiva a que se refere Bourdieu (1989), requer dos tradicionalistas um esforço constante que caracterizo como sua dimensão educacional e de atuação pedagógica. Isso se dá dentro e fora de territórios reconhecidos como espaços tradicionalistas, visando tanto à formação dos jo-

10. A questão do uso da publicidade pelos tradicionalistas e da veiculação de seus símbolos se insere no contexto de proliferação da publicidade regional. A LG e a Coca-Cola são exemplos disto no Rio Grande do Sul, embora, segundo Jacks (1998, p.93 e 97), os tradicionalistas se oponham a veiculação de seus símbolos. No caso da publicidade da Claro Digital, porém, é preciso salientar que a utilização dos símbolos tradicionalistas e das próprias Missões traz vantagens econômicas para ambos os lados, razão prática da concordância decorrente da atuação simbólica. 
vens tradicionalistas como à ampliação de seu universo de culto. Para Manoelito Carlos Savaris, ex-presidente do MTG e atual coordenador do Instituto Gaúcho de Tradição e Folclore - IGTF:

O CTG tem lá o foco, qual é: preservação, resgate e divulgação da história, dos aspectos históricos, folclóricos e evidentemente tradicionais. Há todo um estímulo para que os CTGs façam essa volta lá atrás e representem diversos aspectos no hoje. Como é que nós podemos fazer isso? Nós podemos fazer isto de muitas formas, mas a forma que nós encontramos mais fácil e que mais cala, que mais tem significado nas pessoas é via dança, via música e via dança. Claro que também algumas iniciativas de teatro. Tem algumas iniciativas muito interessantes da área do teatro nos CTGs, tá. Mais isso via dança, via representação que na verdade é quase um teatro, é que eles fazem. De pegar determinados aspectos do folclore, da história e representá-los hoje, fazendo uma viajem no tempo. Então esta relação da história como uma coisa inanimada, uma coisa distante inatingível quase pra muitas pessoas, ta! Se corporifica nestas atividades que são feitas, porque nós entendemos que é mais fácil se ensinar história, fazendo, utilizando um grupo de dança pra fazer a reconstrução. Por exemplo, no Enart do ano passado, um CTG de Porto Alegre o Raízes do Sul representou a Guerra Guaranítica, certo? Aquela representação deles ali ela foi uma aula de história melhor do que muitas palestras que nós pudéssemos fazer para aquela juventude e não só das pessoas que fizeram a apresentação e das famílias envolvidas nisso porque tem ali doze pares, doze jovens dançando, mais seis ou sete na parte da música, então são então trinta pessoas, mas estas trinta pessoas carregam consigo pelo menos mais três ou quatro cada um. Já chegamos a 100, I 30 pessoas envolvidas naquele processo e compreendendo como é que aquele fato se deu na história e isso se apresenta lá no Enart que todo mundo vê e isso desperta curiosidade, desperta interesse de leitura, desperta interesse de saber como é que foi, desperta discussão também de que não foi bem assim e isso também é importante. (Entrevista )

Sua manifestação se relaciona ao uso do passado feito pelos grupos de dança tradicionais do estado como um recurso pedagógico a serviço do tradicionalismo gaúcho. Neste sentido, o CTG pode ser pensado como um espaço de educação informal, em que se comunicam múltiplos saberes. Assim 
como nesse episódio, a história é produzida pelo grupo para ser introjetada como mito, na expressão de Augé (2003).

Essa constante referência ao passado em busca da afirmação das identidades pelos tradicionalistas como grupo, remete aos Centros de Tradições Gaúchas como espaços ritualizados. Na perspectiva de Rivière (2000), o rito se aproxima da cerimônia. A representação ritual extrapola a questão da manutenção da ordem, remetendo a repercussões afetivas como fator unificador do social em que se percebe o jogo das diferenças e hierarquias.

Nas representações do gaúcho tradicionalista há todo um conjunto de comportamentos e valores a que suas lideranças se referem como ética. Esta permeia suas atividades nas representações do que é ser gaúcho e de como se devem cultuar as tradições" ${ }^{\prime}$.

No caso apresentado, o caráter da criação se insere e tem por objetivo o concurso de danças que, segundo o regulamento do Enart, consiste na apresentação pelas invernadas artísticas de três danças tradicionais, sorteadas do Manual de danças, de Cortes e Lessa (1956), perante a comissão avaliadora. Nesta perspectiva, é necessário perceber os processos educacionais e pedagógicos do tradicionalismo, que visam a formação dos jovens tradicionalistas e de suas famílias no seio dos CTGs. Isso se dá por meio do tornar-se tradicionalista (participação nas atividades do CTG), de cursos promovidos pelo MTG e demais instâncias tradicionalistas, e também por sua inserção nas escolas, estabelecendo um novo território tradicionalista e possível reprodutor de sua filosofia e modelos comportamentais.

Constituem atividades tradicionalistas as referidas como eventos oficiais do MTG que ocorrem anualmente: Congresso Tradicionalista, Convenção Tradicionalista, Enart, Festa Campeira, Concurso de Prendas, bem como o conjunto de atividades que se desenvolvem dentro dos CTGs, como os fandangos, os ensaios dos grupos de danças tradicionais, os saraus de prendas, os concursos internos dos CTGs, entre outros. Sobre os concursos de dança, uma "prenda"'2, por ocasião do Enart, assim se expressou:

I I. Há um documento denominado "Código de ética tradicionalista" cujo objetivo é regrar "a conduta social das pessoas físicas que atuam no meio tradicionalista sob a orientação do MTG". (MTG, 200I, p. I20).

12. O termo, segundo Nunes (1993, p.395), significa um objeto de valor que passa a designar a mulher no universo tradicionalista. 
Eu dançava lá em Uruguaiana e nunca participei de Enart, nem pensava em concurso, nem por isso eu achava menos importante ou gostava menos de dançar. Eu acho que te motiva assim, tu passa o ano inteiro esperando este momento, e depois que tu sai daqui tu sabe que tu pode ter uma semana de folga, mas depois tu vai tocar de novo pro ano que vem e assim tu vai indo, quando tu vê fazem [sic] dez anos que tu dança. (Entrevista, 200 I)

É nestes eventos (concursos, festas, seminários/cursos) e no cotidiano do CTG que ocorre a vivência dos jovens tradicionalistas, o que caracterizo como um processo educacional que leva ao desenvolvimento de atividades tradicionalistas e produção de uma série de representações do ser tradicionalista, que busca afirmar suas identidades grupais, mediante "inserção e imersão" individual de seus membros, nesse universo. A educação, segundo Brandão, está inserida no âmbito da cultura, não se restringindo à escolarização:

Uma dimensão ao mesmo tempo comum e especial de tessitura de processos e de produtos, de poderes e de sentidos, de regras e de transgressão de regras, de formação de pessoas como sujeitos de ação e de identidades e de crises de identificados, de invenção de reiterações de palavras, valores, idéias e de imaginários com que nos ensinamos e aprendemos a sermos quem somos. (2002, p.25)

Nesse sentido, o tradicionalismo como movimento cultural organizado possui dimensões educacionais perceptíveis nas suas representações, como no caso da produção da arte tradicionalista, conforme declarou outra prenda, por ocasião do Enart:

Prá nós é..., tem maneiras de cultuar. Tem gente que não concorda, que acha que não é assim. Eu com o curso Desenho e Plástica na universidade tenho duas formas de ver a arte: eu vejo como dançarina, dançar prá mim é o máximo, eu acho que isso é artístico, as pessoas estão num palco são bailarinos, por esse lado do trabalho, do ensaio eu vejo como arte. Agora vendo dentro do contexto da arte, do que os artistas falam dançar não é uma arte, no conceito deles não: dançar é dançar, é um divertimento a arte é outra coisa bem diferente é estudo de pintores, de filósofos. E outra consideração é de que por trás da nossa dança 
tem uma baita parte histórica. Tem um lado histórico, mas há tempos atrás isso era comum, era corriqueiro, não era arte. Prá nós agora que estamos fazendo uma representação do passado, agora nós achamos que é uma arte, antes não era uma arte era o convívio, o dia a dia das pessoas, iam num baile dançar. (Entrevista, 200I)

A fala é elucidativa, pois remete a dois tipos de classificação. Uma reconhecida por ela como a erudita, que exclui a dança de modo geral como arte, e outra valorizadora de suas peculiaridades, em que a dança tradicionalista é considerada, por seu caráter, como arte, porque faz uma leitura do passado. Não é o tradicionalismo que é arte. Dançar em "fandango", por exemplo, não é arte por seu caráter de divertimento. Segundo a jovem, o caráter histórico e a produção da representação conduzem à arte, bem como o trabalho de criação e aperfeiçoamento técnico, abrangendo os dois critérios, a criatividade e a técnica.

Essa classificação é importante para entender a circulação entre o universo douto e a cultura popular a que se refere Ginsburg (200 I , p.23), vivenciado pelo grupo. No caso dos tradicionalistas, esse desejo incessante de classificação, regramento de condutas e padrões a serem seguidos, regulamentos, necessidade de reconhecimento legal e chancela de cientificidade suscita certa dubiedade em suas relações com a cultura popular se esta for percebida, em seu sentido estrito, como pura e romântica expressão do folk. Cabe lembrar os conhecidos argumentos de Chaui, para além do conformismo e da resistência, no que se refere à cultura popular:

Isto é, o mais importante no momento é perceber que interpretações ambíguas, paradoxais, contraditórias que co-existem no mesmo sujeito, criando a aparência de incoerência, na verdade exprimem um processo de conhecimento, a criação de uma cultura ou de um saber a partir de ambiguidades que não estão na consciência desta população, mas na realidade em que vivem. ( 1996, p. I 58)

Nessa perspectiva, como propôs também Certeau (2005), cabe repensar as autoritárias e desgastadas classificações de cultura, valorizando então a dimensão da cultura como arte da invenção do quotidiano e desta como educação, em termos da produção de práticas sociais com significado para aquele que a realiza. 
A percepção da arte tradicionalista por meio da dança pode ser interpretada como produção de conhecimento com fins educacionais, no sentido de oferecer uma leitura do passado pela linguagem tradicionalista, construindo um universo de culto às tradições, inclusive para não tradicionalistas que assistem a essas encenações. A arte tradicionalista se relaciona à produção de um universo imaginário pedagogizado para se viver o mito do gaúcho, cuja recepção passa pela repercussão que esse imaginário consegue ter, conforme Oliven (2006).

Os CTGs e outros territórios tradicionalistas e do gauchismo são espaços educacionais que objetivam sua reprodução e sua perpetuação como movimento cultural. A educação, nesse caso, se inscreve no aprendizado de identidades culturais de um grupo. Mas inscreve-se também como norteadora de identidades individuais (Brum, 2008). Assim, em termos de tradicionalismo, cabe a reflexão sobre a homogeneidade e a heterogeneidade nos processos de formação do ser tradicionalista. Do que decorre que o ser gaúcho tradicionalista adquire múltiplas significações para cada um de seus participantes e para o grupo, sendo continuamente interpretado e dinamizado.

Por sua convergência com os ideais integracionistas do tradicionalismo, vale lembrar as tradicionais abordagens de educação e pedagogia de Durkheim, para quem a educação é pensada como um processo contínuo e a pedagogia como intermitente. São teorias práticas que servem como plano de atuação, como modelos a serem implementados. A educação é relativa à moral e propicia a integração do indivíduo ao grupo, tendo o compromisso de fazer com que os indivíduos partilhem das representações coletivas e as difundam: "O homem, que a educação deve realizar em cada um de nós, não é o homem que a natureza fez, mas o homem que a sociedade quer que ele seja e, ela o quer, conforme o reclame a sua economia interna, o seu equilíbrio" (Durkheim, s/d., p.8I).

Entre os tradicionalistas há esta preocupação moral, o desejo de levar a toda a sociedade gaúcha seus ideais e o compromisso apregoado da afirmação de valores da amizade, solidariedade, da família como instituição primordial. Valores que se expressam nas atividades tradicionalistas, cujas produções de sentido remetem e encontram respaldo em uma ética tradicionalista, conforme explicita Lima: 
Para nós rio-grandenses, a visão conceitual de cidadania e tradicionalismo é relevante. Somos uma sociedade consolidada na consciência desta comunhão de valores. $\bigcirc$ tradicionalismo gaúcho tem se desenvolvido nesta direção. Gaspar, Pinheiro Machado, Félix da Cunha, Castilhos, entre tantos, de longa data com sua inteligência e sabedoria, apontam caminhos e princípios que, hoje, constituem um patrimônio moral, uma riqueza ética, uma cultura, uma identidade. (Lima, 2004, p. |43)

\section{O TRADICIONALISMO E A ESCOLA}

Ao longo do texto, mencionei as estratégias do tradicionalismo para a consolidação do gaúcho como símbolo regional e o desejo de ampliação do seu universo do culto às tradições. A situação é justificada pelo MTG, mediante o discurso de uma atuação social do movimento tradicionalista que se direciona também às escolas. Estas, ao incentivarem seus alunos a se vestirem a caráter, "se pilcharem", durante o mês de setembro, quando oficialmente se comemora o gaúcho como tipo característico do Rio Grande do Sul, produzem a vivência do típico, exaltando um passado heróico e belicoso. As celebrações compreendem múltiplos elementos, tais como: a eleição de certos fatos da história para serem celebrados, a afirmação do território do Rio Grande do Sul como local a que se declara pertencimento, a seleção de costumes etc.

A presença do tradicionalismo nas escolas extrapola muitas vezes o mês de setembro. Algumas escolas no Rio Grande do Sul possuem, inclusive, departamentos tradicionalistas ("CTG em miniatura", para celebrar o típico no cotidiano da escola), com professores responsáveis por suas atividades, que incluem grupos de danças tradicionais gaúchas e seu ensino, aulas de folclore e tradicionalismo e temas relativos aos conteúdos programáticos de história e geografia do Rio Grande do Sul. Há projetos desenvolvidos por "prendas" e "peões" de CTGs ${ }^{13}$, vinculados ao Movimento Tradicionalista Gaúcho que,

13. Projetos como o MTG Vai à Escola são parte obrigatória do desenvolvimento dos concursos de "prenda" e "peão farroupilha" do Rio Grande do Sul, promovidos pelo MTG. Inegavelmente, constituem uma aproximação das escolas pelo MTG, porém, estas se queixam do trabalho desenvolvido pelos jovens tradicionalistas, que muitas vezes fica inacabado após a realização do concurso em que elas estão envolvidas. A realização dos concursos tradicionalistas tem 
ao apresentarem as tradições gaúchas a serem vividas na escola, o fazem de acordo com a imagem produzida e vivida como mito no CTGs. Há ainda, a produção de textos que fazem a interlocução entre a formação dos jovens tradicionalistas e as escolas. Neste contexto, em 2008, foi publicado Nossos símbolos: nosso orgulho. A cartilha é uma coletânea organizada por Manoelito Carlos Savaris, publicada pelo IGTF, e destinada às escolas e CTGs, visando esclarecer sobre o culto das tradições:

O caso específico deste trabalho, e do temário da Semana Farroupilha, diz respeito aos símbolos de pertencimento que funcionam como imagens identificadoras. Bom exemplo nos oferece o Benfato ao dizer "os apreciadores do futebol tem sua expressão maior de pertencimento esportivo na condição de torcedores ou do Grêmio ou do Internacional. (Savaris, 2008, p.7)

Por que é importante trabalhar os símbolos?

É importante porque cada um dos símbolos traz consigo um significado histórico e de relacionamento com a identidade regional. Esse conhecimento facilitará o fortalecimento do sentimento de amor e de apego às raízes e tradições da sociedade gaúcha, criando-se uma barreira psicológica de proteção da identidade regional. Isso não significa desconhecer ou desprezar outras culturas ou alternativas presentes. (Savaris, 2008, p. 174)

Mas, apesar da existência de todo um conjunto de ações por parte do tradicionalismo, remetendo a sua atuação junto à escola, há uma contradição nessas relações que merece ser analisada. Do ponto de vista das escolas, o contato com o tradicionalismo como movimento para ser vivido no seu interior surge também da procura da própria escola como instituição, por intermédio da atuação de seus professores, como no caso de uma escola estadual de Santa Maria. As atividades tradicionalistas nessa escola se iniciaram em 1996, graças à atuação de duas professoras que participavam com suas famílias em CTGs.

como objetivo, genericamente, provar em diferentes modalidades artísticas ou campeiras a maior fidelidade nas representações relativas ao passado do gaúcho. Essa dimensão da competitividade é importante para se entender o grande afluxo de pessoas ao tradicionalismo, em termos de sua realização pessoal, reconhecimento e poder de agência, na perspectiva de Ortner (2007), no universo tradicionalista. 
Sua atuação na escola partiu da constatação de que os valores tradicionalistas e seus costumes seriam importantes na formação dos alunos. Na escola, situada em um bairro popular, um projeto e uma fita de vídeo foram elaborados e enviados à Secretaria da Educação do Estado e ao MTG. Dessa iniciativa, curiosamente, não obtiveram nenhum retorno.

Porém, apesar da confluência de tradições exaltadas e da própria representação identitária "do ser tradicionalista gaúcho" no espaço da escola, por conta da atuação de uma das professoras, percebe-se que o campo do tradicionalismo dos CTGs é diverso do tradicionalismo das escolas. Ensinar os alunos a viverem as tradições por meio de várias expressões artísticas, de acordo com as representações preconizadas, passa pela necessidade de formação dos valores e do conhecimento da história e dos costumes do Rio Grande do Sul pelos alunos, na perspectiva de uma valorização do civismo. "Ao se envolver com o tradicionalismo, uma atividade saudável, o aluno não se envolve com o que não deve se envolver" (Diário de campo, 7/8/2006).

A representação produzida pelas professoras sobre o tradicionalismo do CTG, apesar de elas também fazer parte desse universo, é bastante crítica: "Os CTGs usam as escolas na hora de montar os grupos de dança e desmantelam os nossos grupos, mas o lado bom de tudo isso é que os alunos seguem no tradicionalismo e a escola faz a sua parte de encaminhar o aluno para a cultura" (Diário de campo, 7/8/2006).

O CTG, nesse sentido, é percebido como uma instituição que se aproxima da escola para formar seus quadros de dança e para que os jovens tradicionalistas (peões e prendas) possam desenvolver seus projetos, sem que haja uma preocupação efetiva com o desenvolvimento e rumos do tradicionalismo na escola como instituição educacional.

A relação descrita escola/tradicionalismo reflete os meandros e embates da construção de um imaginário catalisador no gauchismo, pela atuação dinâmica dos múltiplos atores de um movimento que interpreta o gaúcho para utilizá-lo como símbolo no presente.

Para além das discussões acerca do tradicionalismo como uma tradição inventada, na perspectiva de Hobsbawm e Ranger ( 1984), ou da própria autenticidade advogada por esse vasto grupo que se designa tradicionalista no sentido essencialista "de como realmente viveu o gaúcho", é inegável reconhecer a declaração de pertencimento na construção coletiva e individual das identida- 
des regionais. Elas são acionadas pelo fascínio exercido pelo gauchismo em seu poder de significar o presente de quem dele participa: "CTG é uma cachaça", "tradicionalismo é minha religião", "somos uma família". Trata-se de comunidade afetiva de sentimentos, expressa em seus ritos como o elo regional na utilização simbólica do gaúcho, que peculiariza o tradicionalismo como cultura popular.

\section{REFERÊNCIAS BIBLIOGRÁFICAS}

AUGÉ, M. Temps en ruines. Paris: Galilée, 2003.

BOURDIEU, P. O Poder simbólico. Rio de Janeiro: Bertrand Brasil, Difel, 1989. (col. Memória e Sociedade)

BRANDÃO, C. R. A Educação como cultura. Campinas: Mercado das Letras, 2002.

BRUM, C. K. "Esta terra tem dono": representações do passado missioneiro no Rio Grande do Sul. Santa Maria: Ed. UFSM, 2006.

"Educar para ser gaúcho": apontamentos sobre as relações entre Movimento Tradicionalista Gaúcho e a escola. In: CUNHA, J. L. et al. (orgs.) Escola, conflitos e violências. Santa Maria: Ed. UFSM, 2008. p.33-60.

CHAUI, M. Conformismo e resistência: aspectos da cultura popular no Brasil. 6. reimpr. São Paulo: Brasiliense, 1996.

CERTEAU, M. de. A Cultura no plural. 4.ed. São Paulo: Papirus, 2005.

CORTES, J. C. P. Origem da semana farroupilha e primórdios do movimento tradicionalista. Porto Alegre: Evangraf, 1994.

CORTES, J. C. P.; LESSA, L. C. B. Manual de danças gaúchas. Porto Alegre: CGF, 1956.

DURKHEIM, É. Educação e sociologia. São Paulo: Melhoramentos, s/d.

FRADKIN, R. O. Centauros de la pampa: le gaucho entre l'histoire et le mythe. Annales: Histoire, Sciences Sociales, Paris, v.58, n. I, p. I09- I33, jan.ffev. 2003.

GARAVAGLIA, J. C. Gauchos: identidad, identidades. Paris: Cerma, 2003.

GINSBURG, C. Olhos de madeira: nove reflexões sobre a distância. São Paulo: Companhia das Letras, 200 I.

HOBSBAWM, E.; RANGER, T. A Invenção das tradições. Rio de Janeiro: Paz e Terra, 1984.

JACKS, N. Mídia nativa: indústria cultural e cultura regional. Porto Alegre: UFRGS, 1998. 
KAISER, J. Ordem e progresso: o Brasil dos gaúchos. Florianópolis: Insular, 1999.

LESSA, B. L. C. Nativismo: um fenômeno social gaúcho. Porto Alegre: LPM, 1985.

LIMA, J. Tradicionalismo... responsabilidade social: reflexões. Porto Alegre: MTG, 2004.

LÖFGREN, O. The Nationalization of culture. Ethnologia Europaea, v. I 4, n.7, p. 5-24, 1989.

MACIEL, M. E. Le Gaucho brésilien: identité culturelle dans le sud du Brésil. Paris, 1994. Tese (dout.) Université Paris V.

Memória, tradição e tradicionalismo no Rio Grande do Sul. In: BRESCIA-

NI, S.; NAXARA, M. Memória e (res)sentimento: indagações sobre uma questão sensível. Campinas: Unicamp, 200 I. p.239-267.

MTG. Coletânea da legislação tradicionalista. 2.ed. rev. e ampl. Porto Alegre: MTG, 200 I. Relatórios de atividades dos anos 1998-200 I. Porto Alegre: Brindes, 2002.

NUNES, Z. Dicionário de regionalismos do Rio Grande do Sul. Porto Alegre: Martins Livreiro, 1993.

OLIVEN, R. A Parte e o todo: a diversidade cultural no Brasil-nação. 2.ed. Petrópolis: Vozes, 2006.

ORTNER, S. Poder e projetos: reflexões sobre a agência. In: GROSSI, M et al. (orgs.) Conferências e diálogos: saberes e práticas antropológicas. Brasília: ABA, Nova Letra, 2007. p.45-80.

PADOIM, M. M. A Revolução Farroupilha. PICCOLO, H. I. L. et al. Império. Passo Fundo: Méritos, 2006. p.39-69.

PESAVENTO, S. História do Rio Grande do Sul. Porto Alegre: Mercado Aberto, 1990.

QUEVEDO, J. Guerreiros e jesuítas na utopia do Prata. São Paulo: Edusc, 2000.

RIVIÈRE, C. Ritos profanos. Petrópolis: Vozes, 2000.

ROCHA, E. P. G. Magia e capitalismo: um estudo antropológico da publicidade. São Paulo: Brasiliense, 1985. Publicidade e razão prática, p.62-73.

SAVARIS, M. C. (org.) Nossos símbolos: nosso orgulho. Porto Alegre: IGTF, 2008.

THIESSE, A. A Construção das identidades nacionais. Lisboa: Temas e Debates, 2001 .

TEIXEIRA, S. A. Os Recados das festas. Rio de Janeiro: Funarte, 1988.

Recebido em: junho 2009.

Aprovado para publicação em: julho 2009. 